\title{
Effect of Sn Incorporation on Physical Parameters of Sb-Se Glassy System
}

\author{
R. Khajuria ${ }^{1}$, A. Sharma ${ }^{*}$, P. Sharma ${ }^{2}$ \\ ${ }^{1}$ Department of Physics, Maharaja Agrasen University, Baddi, Solan (H.P.), India \\ ${ }^{2}$ Department of Physics, Abhilashi University Nerchowk, Mandi (H.P.), India
}

Received 20 March 2020, accepted in final revised form 6 June 2020

\begin{abstract}
The rationale of this study is to investigate band gap tailoring of Sb-Se-Sn chalcogenide glasses. This study has been accompanied by the assessment of various theoretical parameters such as average co-ordination number, Lone-pair of electrons, number of constraints, average heat of atomization, mean bond energy and glass transition temperature. It has been observed that almost all these physical parameters have been enhanced with the increase in tin $\mathrm{Sn}$ ) content except Lone-pair of electrons. The number of lone-pair electrons has been decreased with the increase in Sn content. The glass transition temperature has been observed to increase due to the addition of $\mathrm{Sn}$ atom in the $\mathrm{Se}-\mathrm{Sb}$ glassy system. The band gap is decreasing with increase in Sn content due to overall decrease in the average single bond energy of the $\mathrm{Sb}-\mathrm{Se}-\mathrm{Sn}$ glassy system.
\end{abstract}

Keywords: Sb-Se-Sn; Chalcogenide glasses; Melt quenching; Co-ordination number; Average heat of atomization; Band gap.

(C) 2020 JSR Publications. ISSN: 2070-0237 (Print); 2070-0245 (Online). All rights reserved. doi: http://dx.doi.org/10.3329/jsr.v12i4.46048

J. Sci. Res. 12 (4), 545-554 (2020)

\section{Introduction}

Chalcogenide glasses are considered as single molecular complex having large covalent bonds. These glasses are formed by sulphur (S), selenium (Se) and tellurium (Te). Some dopants like germanium (Ge), arsenic (As), antimony ( $\mathrm{Sb}$ ), etc. are also added for their formation. Reversible phase transformation is well noticed in Se and is widely used as amorphous semiconductor in photocells, Xerography, memory switching etc. [1]. Se is considered as good material for making chalcogenides but it is having the disadvantage of smaller life span and deprived sensitivity. Due to this reason, Se is doped with other impurity atoms like $\mathrm{Ge}, \mathrm{In}, \mathrm{Sb}$ etc. to enhance sensitivity, crystallization temperature and reduce ageing effects [2]. Chalcogenide glasses are considered special because their transmission exists in the middle and far-infrared spectra and refractive index is also high [3].

\footnotetext{
Corresponding author: anshu.hpu@gmail.com
} 
Chalcogenide glasses have several useful properties in the fields of infra-red optical elements, optical fibres and storage apparatus [4,5]. A large variation in physical properties is noticed by small variations in chemical compositions. Formation of such alloys is mostly done by melt-quenching technique [6]. Chalcogenide glasses are considered as amorphous semiconductors because of non-availability of larger-range order. This property of amorphous semiconductors helps in modifying optical properties by altering its chemical composition [7]. By observing the connection of optical properties and chemical variations of the Sb-Se-Sn glassy system, we can manufacture a wide range of optical devices [8]. Chalcogenide glasses are also known as lone pair semiconductors and these lone pairs are responsible for chemical disorder. By varying the composition of $\mathrm{Sn}$ in Sb-Se glassy system, there is variation in bond formation leading to structural change in Sb-Se-Sn [9]. Also by variation of $\mathrm{Sn}$ in Se based chalcogenide glasses, there is increase in semiconducting properties of the material [10]. The Sb-Se system is considered good for research work due to better hardness and high crystallization temperature. Addition of the element tin ( $\mathrm{Sn}$ ) may bring changes in electrical and optical properties of Sb-Se system significantly. Sharma et al. [11] reported that the addition of metal impurities increase the refractive index and thus significantly lower the optical band gap.

The main emphasis of present work is to study the system $\mathrm{Sb}_{14} \mathrm{Se}_{86-\mathrm{x}} \mathrm{Sn}_{\mathrm{x}}(\mathrm{x}=0,3,6,9$, 12 , 15) theoretically. Theoretical studies have been carried out to calculate the coordination number, constraints number, quantity of lone pair electrons, bond energies of compositional elements, atomization heat, energy of cohesion, energies of mean bond and transition temperature of the glassy alloy has been calculated by taking in account the model projected by Tichy and Ticha $[12,13]$. The variation in concentration of Sn used to create compositional and configurationally disorder in the material. It has been established that physical properties in this system are highly composition dependent. The present work is concerned with theoretical predictions of some physical parameters related to composition.

\section{Experimental}

The samples of $\mathrm{Sb}_{14} \mathrm{Se}_{86-\mathrm{x}} \mathrm{Sn}_{\mathrm{x}}(\mathrm{x}=0,3,6,9,12,15)$ glassy system were prepared by conservative melt quench procedure. High purity elements $\mathrm{Sb}, \mathrm{Se}, \mathrm{Sn}$ of $99.99 \%$ purity (CDH Brand, India) were taken with respect to their atomic percentages and were sealed in vacuated $\left(10^{-4} \mathrm{~Pa}\right)$ quartz ampoules. Before sealing, quartz ampoules were washed with concentrated $\mathrm{H}_{2} \mathrm{SO}_{4}$ followed by cleaning with distilled water. Then sealed ampoules were kept inside muffle furnace (BST/MF/1100, India) and temperature was increased up to $1000{ }^{\circ} \mathrm{C}$ with a heating rate of $3-4{ }^{\circ} \mathrm{C} / \mathrm{min}$. The ampoules were then frequently rocked for $9 \mathrm{~h}$ to make the homogenous melt. Cold treatment was instantly given to the samples so that their amorphous nature is maintained with the help of melt quench technique. The next step was to extract the material from the quartz tubes. The material was grinded to 
fine powders and the samples were utilized for X-ray diffraction analysis. The detailed experimental technique has been given elsewhere [14].

\section{Results and Discussion}

\subsection{Estimation of co-ordination number (m) and number of constraints}

Co-ordination number is the number of atoms, molecules or ions bounded to the central atom. The coordination number depicts the number of orbital available for bonding and it depends on the geometrical arrangement of the ligands. The calculation of average coordination number for $\mathrm{Sb}_{14} \mathrm{Se}_{86-\mathrm{x}} \mathrm{Sn}_{\mathrm{x}}(\mathrm{x}=0,3,6,9,12,15)$ glassy system has been done by the following formula [15]:

$m=\frac{\alpha N_{S b}+\beta N_{S e}+\gamma N_{S n}}{100}$

Here $\alpha, \beta$ and $\gamma$ are the atomic $\%$ of $\mathrm{Sb}$, Se and $\mathrm{Sn}$ respectively and $\mathrm{N}_{(\mathrm{Sb}),} \mathrm{N}_{(\mathrm{Se})}, \mathrm{N}_{(\mathrm{Sn})}$ are their respective coordination numbers. The co-ordination numbers of $\mathrm{Sn}, \mathrm{Sb}, \mathrm{Se}$ have been calculated $4,3,2$ respectively by $8 \mathrm{~N}$ rule. The average coordination number $\langle\mathrm{m}\rangle$ is necessary parameter for the ternary $\mathrm{Sb}_{14} \mathrm{Se}_{86-\mathrm{x}} \mathrm{Sn}_{\mathrm{x}}(\mathrm{x}=0,3,6,9,12,15)$ glassy system to test the validity of topological concepts because of its large glass forming domain [4]. By varying content of $\mathrm{Sn}$ in $\mathrm{Sb}-\mathrm{Se}-\mathrm{Sn}$ glassy system, there is an increase of average coordination number from 2.14 to 2.44 . A prominent increase in the co-ordination number is clearly seen in Table $1(2.14 \leq \mathrm{m} \leq 2.44)$ which evidently indicates the increase in tendency of cross linking of atomic chains in $\operatorname{Sb}_{14} \mathrm{Se}_{86-\mathrm{x}} \mathrm{Sn}_{\mathrm{x}}(\mathrm{x}=0,3,6,9,12,15)$ system. Thus, the glassy system under observation is compactly packed and amorphous in nature. According to constraint theory, mechanical constraints $\left(\mathrm{N}_{\mathrm{c}}\right)$ plays an important role in explaining glass forming behavior. Mechanical constraints have close association with atomic bonding and the average coordination number $(\mathrm{m})$. Covalent solids are associated with two types of bonding forces viz. bond-stretching $\left(\mathrm{N}_{\mathrm{a}}\right)$ and bond-bending $\left(\mathrm{N}_{\mathrm{b}}\right)$ which are directly linked with the structural formation of the glassy network. For a glassy system with average coordination number $(\mathrm{m})$, bond-stretching $\left(\mathrm{N}_{\mathrm{a}}\right)$ and bond-bending $\left(\mathrm{N}_{\mathrm{b}}\right)$ parameters are given by: bond-stretching $\left(\mathrm{N}_{\mathrm{a}}\right)=\mathrm{m} / 2$; and bond-bending $\left(\mathrm{N}_{\mathrm{b}}\right)=2 \mathrm{~m}-3$. The addition of bond-stretching and bond-bending forces gives average number of total constraints $\left(\mathrm{N}_{\mathrm{c}}\right)$ :

$\mathrm{N}_{\mathrm{c}}=\mathrm{N}_{\mathrm{a}}+\mathrm{N}_{\mathrm{b}}$

The effective co-ordination number is given by:

$\left\langle\mathrm{m}_{\mathrm{eff}}\right\rangle=2 / 5\left(\mathrm{~N}_{\mathrm{c}}+3\right)$

The values of bond-stretching $\left(\mathrm{N}_{\mathrm{a}}\right)$, bond-bending $\left(\mathrm{N}_{\mathrm{b}}\right)$, average number of total constraints $\left(\mathrm{N}_{\mathrm{c}}\right)$ and effective co-ordination number $\left\langle\mathrm{m}_{\mathrm{eff}}\right\rangle$ are listed in the Table 1. 
According to Phillips and Thorpe [16,17], the best possible glass compositions are those in which the number of constraints exactly equals the degrees of freedom which lead towards the isotactic structure of the glassy system. The arrangement of atoms in the minimum energy state pattern in crystalline status is very easy and smooth in the floppy regime (mean co-ordination number < 2.4). Also there is easy percolation of the rigid structures all through the system in the over-constrained regime (mean co-ordination number > 2.4) which also results in crystallization. The average number of constraints increases with the increase in Sn content. In the present glassy system the best glass formation occurs for $\mathrm{m}=2.44$ for $\mathrm{x}=15$ percentage sample. Thus we can analyze from the constraint theory that there is mechanical softening in covalently bonded networks and as the coordination number increases the glassy network is shifted from floppy mode to rigid mode.

Table 1. Average co-ordination number $(\mathrm{m})$, number of constraints arising from bond stretching $\left(\mathrm{N}_{\mathrm{a}}\right)$, number of Constraints arising from bond bending $\left(\mathrm{N}_{\mathrm{b}}\right)$, average number of Constraints $\left(\mathrm{N}_{\mathrm{c}}\right)$, effective co-ordination number $\left\langle\mathrm{m}_{\text {eff }}\right\rangle$ for $\mathrm{Sb}_{14} \mathrm{Se}_{86-\mathrm{x}} \mathrm{Sn}_{\mathrm{x}}(\mathrm{x}=0,3,6,9,12,15)$ glassy system.

\begin{tabular}{llllll}
\hline Composition & $\mathrm{M}$ & $\mathrm{N}_{\mathrm{a}}$ & $\mathrm{N}_{\mathrm{b}}$ & $\mathrm{N}_{\mathrm{c}}$ & $<$ meff $>$ \\
\hline $\mathrm{Sb}_{14} \mathrm{Se}_{86}$ & 2.14 & 1.07 & 1.28 & 2.35 & 2.14 \\
$\mathrm{Sb}_{14} \mathrm{Se}_{83} \mathrm{Sn}_{3}$ & 2.20 & 1.10 & 1.40 & 2.50 & 2.20 \\
$\mathrm{Sb}_{14} \mathrm{Se}_{80} \mathrm{Sn}_{6}$ & 2.26 & 1.13 & 1.50 & 2.65 & 2.26 \\
$\mathrm{Sb}_{14} \mathrm{Se}_{77} \mathrm{Sn}_{9}$ & 2.32 & 1.16 & 1.64 & 2.80 & 2.32 \\
$\mathrm{Sb}_{14} \mathrm{Se}_{74}$ & 2.38 & 1.19 & 1.76 & 2.95 & 2.38 \\
$\mathrm{Se}_{12}$ & & & & & \\
$\mathrm{Sb}_{14} \mathrm{Se}_{71}$ & 2.44 & 1.22 & 1.88 & 3.10 & 2.44 \\
$\mathrm{Sn}_{15}$ & & & & & \\
\hline
\end{tabular}

\subsection{Role of lone-pair electrons and glass forming ability}

The non-bonding electrons pair lying in valence band is known as lone pair of electrons (L). Chalcogenide glasses possess the lone-pair electrons and the presence of lone-pair electron removes the strain caused by the formation of amorphous materials and will favour glass formation. The difference of valance electrons of the system and shared electrons gives the number of lone-pair of electrons i.e.,

$\mathrm{L}=\mathrm{V}-\mathrm{m}$

where $L$ and $V$ are the lone-pair electrons and valence electrons respectively. It has been proposed by Philips [17] that the introduction of the average coordination number leads to the evaluation of the lone-pair of chalcogenide glassy system. The number of lone-pair of electrons for $\mathrm{Sb}_{14} \mathrm{Se}_{86-\mathrm{x}} \mathrm{Sn}_{\mathrm{x}}(\mathrm{x}=0,3,6,9,12,15)$ glassy system is calculated by using the above relation (4) and the observed values of the lone-pair of electrons have been listed in Table 2. It is observed that the number of lone-pair of electrons decreased with the increase in $\mathrm{Sn}$ content to the $\mathrm{Sb}$-Se glassy system. This is due to the interaction between the $\mathrm{Sn}$ ion and the lone pair electrons of a bridging Se atom. Therefore the interaction decreases the impact of lone-pair electrons in the glass formation. Zhenhua [18] reported a 
simple criterion for calculating the power of a chalcogenide system to maintain its glassy state. This criterion gives the study of number of lone pair electrons needed for obtaining the system in its glassy state. The glass formation ability in chalcogenides has been proposed by Ammar et al. [19]. The Criterion proposes that for a binary system the number of lone-pair electrons must be larger than 2.6 and for ternary system it must be larger than 1. For $\mathrm{Sb}_{14} \mathrm{Se}_{86-\mathrm{x}} \mathrm{Sn}_{\mathrm{x}}(\mathrm{x}=0,3,6,9,12,15)$ glassy system the values of lone pair electrons lie in the range from 3.72 to 3.12 i.e., $\mathrm{L}>3$ for all compositions. Therefore, these compositions are good glass formers.

Table 2. Number of lone-pair of electrons, optical band gap, bond energies of different bonds possible in $\mathrm{Sb}_{14} \mathrm{Se}_{86-\mathrm{x}} \mathrm{Sn}_{\mathrm{x}}(\mathrm{x}=0,3,6,9,12,15)$ glassy system.

\begin{tabular}{lllllc}
\hline Composition & $\mathrm{m}$ & $\mathrm{V}$ & $\mathrm{L}=\mathrm{V}-\mathrm{m}$ & $\begin{array}{l}\text { Bond energy } \\
(\mathrm{eV} / \text { bond })\end{array}$ & $\begin{array}{l}\text { Optical } \\
\text { band gap } \mathrm{E}_{\mathrm{g}} \\
(\mathrm{eV})\end{array}$ \\
\hline $\mathrm{Sb}_{14} \mathrm{Se}_{86}$ & 2.14 & 5.86 & 3.72 & 1.483 & 1.58 \\
$\mathrm{Sb}_{14} \mathrm{Se}_{83} \mathrm{Sn}_{3}$ & 2.20 & 5.80 & 3.6 & 1.908 & 1.54 \\
$\mathrm{Sb}_{14} \mathrm{Se}_{80} \mathrm{Sn}_{6}$ & 2.26 & 5.74 & 3.48 & 1.309 & 1.50 \\
$\mathrm{Sb}_{14} \mathrm{Se}_{77} \mathrm{Sn}_{9}$ & 2.32 & 5.68 & 3.36 & 2.134 & 1.47 \\
$\mathrm{Sb}_{14} \mathrm{Se}_{74} \mathrm{Sn}_{12}$ & 2.38 & 5.62 & 3.24 & 1.906 & 1.43 \\
$\mathrm{Sb}_{14} \mathrm{Se}_{71} \mathrm{Sn}_{15}$ & 2.44 & 5.56 & 3.12 & 1.405 & 1.40 \\
\hline
\end{tabular}

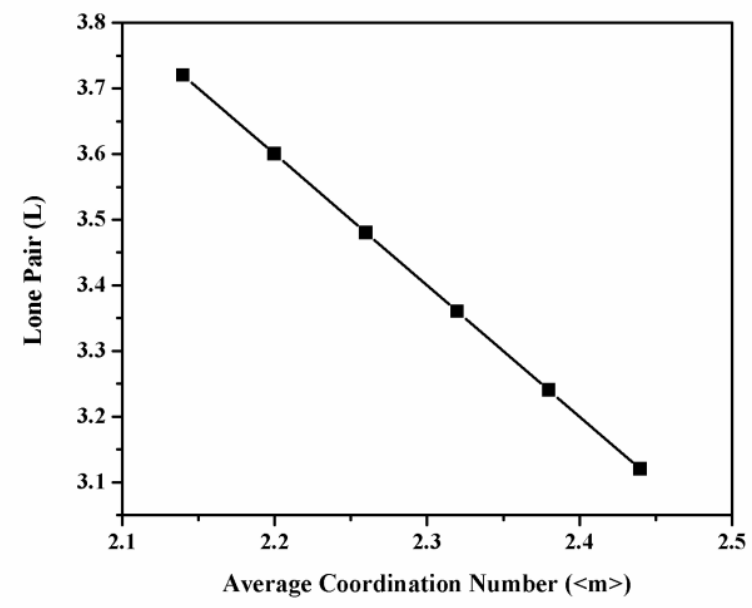

Fig. 1. Variation of lone-pair of electrons (L) with average coordination number $<\mathrm{m}>$ for $\mathrm{Sb}_{14} \mathrm{Se}_{86}$ ${ }_{x} \operatorname{Sn}_{x}(x=0,3,6,9,12,15)$ glassy system.

\subsection{Deviation from the stoichiometry of composition}

The ratio of possible covalent bonds of chalcogen atoms to that of nonchalcogen atoms in the system is known as deviation of stoichiometry $(\mathrm{R})$ which decides the nature of the material i. e., for $R$ greater than 1 the material is chalcogen rich, for $R$ less than 1 the 
material is chalcogen poor and $R$ equal to 1 , is threshold value where heteropolar bonds exists. The value of $R$ plays an immense role in the interpretation of the results. Various chalcogenide systems can be arranged in three categories depending on the value of $R$. If the value of $R$ comes out to be 1 the system reaches the stoichiometry composition. This may be due to the presence of hetero-polar bonds. If the value of $R$ comes out to be greater than 1 the system is chalcogen rich due to the presence of both hetero-polar bonds and chalcogen-chalcogen bonds. If the value of $R$ comes out to be less than 1 the system is chalcogen poor. This may be due to the presence of both hetero-polar bonds and metalmetal bonds. The value of $R$ is obtained by the relation [20-22]:

$R=\frac{a N_{S b}}{b N_{S e}+c N_{S n}}$

In the above equation $a$ is the atomic fraction of $\mathrm{Sb}, b$ is the atomic fraction of $\mathrm{Se}$ and $c$ is the atomic fraction of $\mathrm{Sn} . \mathrm{N}_{\mathrm{Sb}}, \mathrm{N}_{\mathrm{Se}}, \mathrm{N}_{\mathrm{Sn}}$ are the coordination numbers of $\mathrm{Sb}, \mathrm{Se}$ and $\mathrm{Sn}$ respectively. Fig. 2 clearly shows that all the samples of glassy system under investigation is chalcogen rich system i.e., $R>1$. There is a deviation from higher chalcogen region to the lesser chalcogen region with the increase in Sn content but still far away from being chalcogen poor. As the material is chalcogen rich and have high energy lone pair electrons leads to different electron densities.

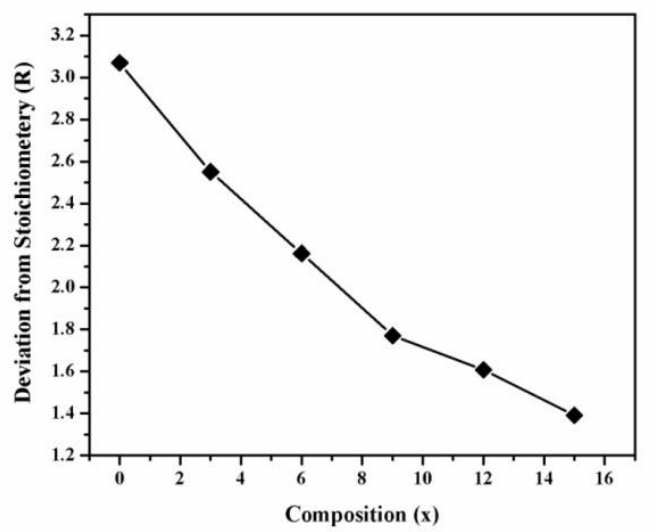

Fig. 2. Deviation of stoichiometry with compositionfor $\mathrm{Sb}_{14} \mathrm{Se}_{86-\mathrm{x}} \mathrm{Sn}_{\mathrm{x}}(\mathrm{x}=0,3,6,9,12,15)$ glassy system.

\subsection{Average heat of atomization}

The properties of semiconducting chalcogenide compounds can be observed with the average heat of atomization. In chalcogenide glasses, there is a high concentration of the group VI element, so the lone pair electrons from the top of the valence band and antibonding band form bottom of the conduction bond [23]. Metal atoms can form a dative bond with group VI atoms correspond to empty antibonding levels which give localized acceptors states in the gap [4]. The optical band gap is linked to the chemical 
bond energy. For the system under investigation, the heat of atomization has been calculated by using relation [24]:

$H_{S}=\frac{\alpha H_{S}^{A}+\beta H_{S}^{B}+\gamma H_{S}^{C}}{\alpha+\beta+\gamma}$

$H_{\mathrm{s}}$ values do not contain the heat of formation because of the electro-negativity of constituent elements i.e., heat of formation is unknown in most of the cases of chalcogenide glasses. The values of heat of atomization for $\mathrm{Sb}$, Se and $\mathrm{Sn}$ are summarized in Table 3 and it is observed that average heat of atomization increases with the increase of $\mathrm{Sn}$ content while the average single bond energy $(\mathrm{m})$ which is a measure of cohesive energy decreases with the increase of Sn content. The decrease in average single bond energy $\left(\mathrm{H}_{\mathrm{S}} / \mathrm{m}\right)$ with the increase in Sn content may cause the decrease of optical band gap [15]. The variation in theoretical optical band gap $\mathrm{E}_{\mathrm{g}}$ with variation in composition has been calculated using the Shimakawa [25] relation;

$\mathrm{E}_{\mathrm{g}}(\mathrm{Sb}-\mathrm{Se}-\mathrm{Sn})=\mathrm{aEg}(\mathrm{Sb})+\mathrm{bEg}(\mathrm{Se})+\mathrm{CEg}(\mathrm{Sn})$

where $a, b, c$ are volume fractions and energy gap values for $\mathrm{Sb}, \mathrm{Se}, \mathrm{Sn}$ and have been taken as $0.101,1.95$ and $0.9 \mathrm{eV}$ respectively. The calculated values have been tabulated in Table 2. It is clear from the table that the optical energy gap decreases with the increase in Sn content. This change in optical band gap may be due to change in average bond energy. Since optical band gap is bond dependent property so decrease in average bond energy results in decrease of optical band gap. According to chemical bond approach, as bond energy decreased there is formation of bonds. The addition of $\mathrm{Sn}$ in $\mathrm{Sb}$-Se network will bring a compositional change in network of Sb-Se system and $\mathrm{Sn}$ atoms will form cross linking network in Sb-Se. Since bond energy of Sb-Se is higher than bond energy of Sn-Se bond, therefore optical band gap decreases with increase in Sn content.

\subsection{Mean bond energy and glass transition temperature}

The mean bond energy $\langle E\rangle$ plays important role in determining many properties of chalcogenide glass material. The mean bond energy depends upon some parameters such as average coordination number, degree of cross-linking, type of bond and bond energy in a system. Tichy and Ticha [13] proposed that the bond energy for each bond, i.e., mean bond energy $\langle E\rangle$, should be taken into account for total networks. The glass transition temperature depends upon mean bond energy $\langle E\rangle$. Mean bond energy $\langle E\rangle$ depends on factors like average coordination number, nature of bonds and degree of cross-linking bond energy. The mean bond energy of the system calculated from the relation.

$\langle\mathrm{E}\rangle=\mathrm{E}_{\mathrm{c}}+\mathrm{E}_{\mathrm{rm}}$

Where $E_{\mathrm{c}}$ is overall contribution towards bond energy from strong bonds and $E_{\mathrm{rm}}$ is the contribution due the weaker bonds in $\mathrm{Sb}_{\mathrm{x}} \mathrm{Se}_{\mathrm{y}} \mathrm{Sn}_{\mathrm{z}}$ (where $\mathrm{x}+\mathrm{y}+\mathrm{z}=1$ ).

In the region of rich selenium concentration

$\mathrm{E}_{\mathrm{c}}=4 x \mathrm{E}_{\mathrm{Sb}-\mathrm{Se}}+3 \mathrm{zE}_{\mathrm{Sn}-\mathrm{Se}}$ 
$E_{r m}=\frac{[2 y-4 x-3 z] E_{S e-S e}}{<r>}$

The calculated values of the mean bond energy are listed in Table 3. It is observed from mean bond energy value that on increasing the Sn content the mean bond energy of the system increases.

Table 3. Average heat of atomization, average single bond energy, mean bond energy, glass transition temperature and deviation from stoichiometry for $\mathrm{Sb}_{14} \mathrm{Se}_{86-\mathrm{x}} \mathrm{Sn}_{\mathrm{x}}(\mathrm{x}=0,3,6,9,12$, 15) glassy system.

\begin{tabular}{llllll}
\hline Composition & $\begin{array}{l}\mathrm{H}_{\mathrm{S}} \\
(\mathrm{eV} / \text { bond })\end{array}$ & $\mathrm{H}_{\mathrm{S}} / \mathrm{m}$ & $<\mathrm{E}\rangle$ & $\mathrm{T}_{\mathrm{g}}(\mathrm{K})$ & $\mathrm{R}$ \\
\hline $\mathrm{Sb}_{14} \mathrm{Se}_{86}$ & 2.401 & 1.121 & 2.102 & 373.82 & 3.07 \\
$\mathrm{Sb}_{14} \mathrm{Se}_{83} \mathrm{Sn}_{3}$ & 2.425 & 1.102 & 2.136 & 384.357 & 2.55 \\
$\mathrm{Sb}_{14} \mathrm{Se}_{80} \mathrm{Sn}_{6}$ & 2.448 & 1.083 & 2.178 & 397.459 & 2.16 \\
$\mathrm{Sb}_{14} \mathrm{Se}_{77} \mathrm{Sn}_{9}$ & 2.472 & 1.065 & 2.228 & 412.972 & 1.77 \\
$\mathrm{Sb}_{14} \mathrm{Se}_{74} \mathrm{Sn}_{12}$ & 2.500 & 1.050 & 2.285 & 430.716 & 1.61 \\
$\mathrm{Sb}_{14} \mathrm{Se}_{71} \mathrm{Sn}_{15}$ & 2.518 & 1.031 & 2.349 & 450.515 & 1.41 \\
\hline
\end{tabular}

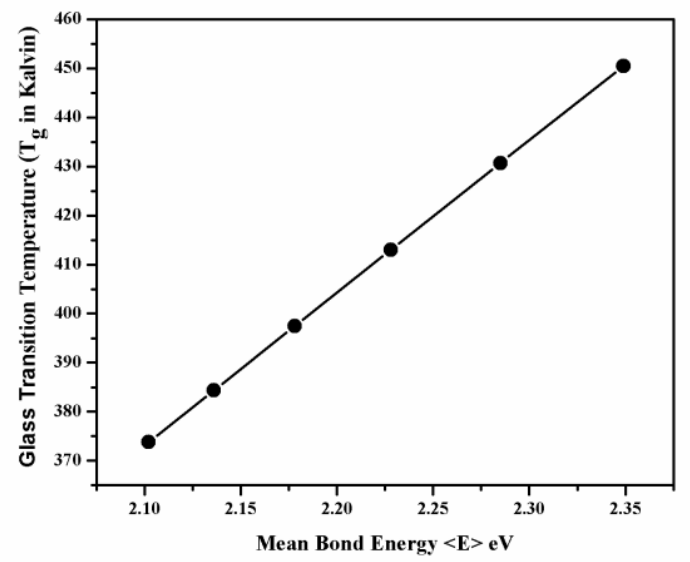

Fig. 3. Variation of glass temperature $T_{g}$ with mean bond energy $\left\langle E>\right.$ in $\operatorname{Sb}_{14} \mathrm{Se}_{86-\mathrm{x}} \mathrm{Sn}_{\mathrm{x}}(\mathrm{x}=0,3,6,9$, $12,15)$ glassy system.

Tichy and Ticha $[12,13]$ theoretically predicted first approximation by covalent bond approach to calculate the glass transition temperature $T_{\mathrm{g}}$ for the chalcogenide glass system. Tichy and Ticha obtained a good correlation between $T \mathrm{~g}$ and $\langle E\rangle$ in the form $\left.\mathrm{T}_{\mathrm{g}}=311[<\mathrm{E}\rangle-0.9\right]$

The above equation satisfies the Arrhenius relation for viscosity. The glass transition temperature of the glassy system $\mathrm{Sb}_{14} \mathrm{Se}_{86-\mathrm{x}} \mathrm{Sn}_{\mathrm{x}}(\mathrm{x}=0,3,6,9,12,15)$ has been calculated and is listed in Table 3. Fig. 3 shows the variation of glass transition temperature with mean bond energy. It is found that the $T_{\mathrm{g}}$ of the $\mathrm{Sb}_{14} \mathrm{Se}_{86-\mathrm{x}} \mathrm{Sn}_{\mathrm{x}}(\mathrm{x}=0,3,6,9,12,15)$ glassy system increases with the increasing $\mathrm{Sn}$ content. This increase in value of $T_{\mathrm{g}}$ may be due 
to the increase in density of samples with increasing dopant concentration which leads to the increased thermal stability of the glassy system.

\section{Conclusion}

The theoretical investigations of various physical parameters for $\mathrm{Sb}_{14} \mathrm{Se}_{86-\mathrm{x}} \mathrm{Sn}_{\mathrm{x}}(\mathrm{x}=0,3,6$, $9,12,15)$ glassy system have been calculated and found that the average coordination number, the number of constraints, average heat of atomization, mean bond energy and $T_{\mathrm{g}}$ increases with the increase of Sn content, while the number of lone-pair of electrons decreases with $\mathrm{Sn}$ content. The stoichiometry parameter $R$ decreases due to decrease in the content of chalcogen Se and increase in contents of Sn. The theoretical optical band gap has been observed to decrease with the Sn content and is well supported by the other empirical results. The increase of $T_{\mathrm{g}}$ favours the formation of heteronuclear bonds between Sn and Se and heteronuclear bonds are preferred to homonuclear ones. Decrease in optical band gap leads to increase in semiconducting properties of chalcogenide glasses and this decreasing trend of optical band gap will be helpful in designing more sensitive detectors and X-ray imaging applications.

\section{References}

1. V. Sharma, S. Sharda, N. Sharma, S. C. Katyal, and P. Sharma, Prog. Solid State Chem. 54, 31 (2019). https://doi.org/10.1016/j.progsolidstchem.2019.04.001

2. P. Sharma, N. Sharma, S. Sharda, S. C. Katyal, and V. Sharma, Prog. Solid State Chem. 44, 131 (2016). https://doi.org/10.1016/i.progsolidstchem.2016.11.002

3. S. Tiwari, A. K. Saxena, and D. Saxena, J. Pure Appl. Sci. Technol. 5, 46 (2011). https://dx.doi.org/10.22161/ijaers/3.10.17

4. L. K. Abhilashi, P. Sharma, R. Vaish, and P. Sharma, Universal J. Phys. Applicat. 9, 58 (2015).

5. Z. H. Khan, M. A. Alvi, and S.A. Khan, J. Acta Physica Polonica A 1, 123 (2013). http://dx.doi.org/10.12693/APhysPolA.123.80

6. M. M. Hafiz, N. E. Kabany, H. M. Kotb, and Y. M. Bakier, J. Thin Films Sci. Technol. 4, 179 (2015).

7. M. Ghayebloo, M. Tavoosi, and M. Rezvani, J. Infrared Phys. Technol. 83, 62 (2017). https://doi.org/10.1016/j.infrared.2017.04.010

8. E. Romanova, Y. Kuzyutkind, V. Shiryaev, N. A. Moneim, and S. Guizard, J. Non Crystalline Solids 480, 13 (2018). https://doi.org/10.1364/OL.31.001495

9. H. E. Atyia, S. S. Fouad, P. Sharma, A. S. Farid, and N. A. Hegab, J. Optoelectronics Adv. Mater. 20, 319 (2018).

10. S. Ahmadpour, M. Rezvani and P. Bovafa, J. Spectrochimica Acta Part A 205, 258 (2018).

11. P. Sharma and S. C. Katyal, Thin Solid Films 517, 3813 (2009). https://doi.org/10.1016/j.tsf.2009.01.106

12. L. Tichy and H. Ticha, J. Non Cryst. Solids 189, 141 (1995). https://doi.org/10.1016/0022-3093(95)00202-2

13. L. Tichy and H. Ticha, Material Lett. 21, 313 (1994). https://doi.org/10.1007/978-94-0100914-0_10

14. P. Sharma and S. C. Katyal, J. Phys. D: Appl. Phys. 40, 2115 (2007). https://doi.org/10.1088/0022-3727/40/7/038

15. J. C. Phillips, J. Non-Cryst. Solids 34, 153 (1979). https://doi.org/10.1016/0022-3093(79)90033-4

16. M. F. Thorpe, J. Non-Cryst. Solids 57, 355 (1983). https://doi.org/10.1016/0022-3093(83)90424-6

17. J. C. Philips and M. Thorpe, Solid State Commun. 53, 699 (1985). 


\section{$554 \quad$ Sb-Se Glassy System}

https://doi.org/10.1016/0038-1098(85)90381-3

18. L. Zhenhua, J. Non-Cryst. Solids 127, 298 (1991).

https://doi.org/10.1016/0022-3093(91)90482-L

19. A. H. Ammar, A. M. Farid, and S. S. Fouad, Physica B 307, 64 (2001). https://doi.org/10.1016/S0921-4526(01)00969-3

20. M. Fadel, Vacuum 48, 73 (1997). https://doi.org/10.1016/S0042-207X(96)00229-1

21. A. Geoge, D. Sushamma, and P. Predeep, Chalcogenides Lett. 3, 33 (2006).

22. M. Kastner, Physics Review Letters 28, 355 (1972). https://doi.org/10.1103/PhysRevLett.28.355

23. V. Modgil and V. S. Rangra, J. Optoelectronics Adv. Mater. 13, 158 (2011).

24. A. Dahshan and K. A. Aly, Philosophical Mag. 88, 361 (2008). https://doi.org/10.1080/14786430701846214

25. K. Shimakawa, J. Non-Cryst. Solid. 43, 229 (1981). https://doi.org/10.1016/0022$\underline{\text { 3093(81)90119-8 }}$ 